\title{
Research on Enterprise's Comprehensive Budget Management System in the View of Big Data and Cloud Accounting
}

\author{
ZUO Xiangli \\ Wuhan Business University, Wuhan, 430056, China \\ E-mail: 1165196272@qq.com
}

Key words: big data, cloud accounting, comprehensive budget management, system building

\begin{abstract}
Comprehensive budget management is an advanced enterprise management model, and a way for enterprises to obtain optimal productivity and profitability of their resources. It plays an important role in the operation and management of enterprises. Big data technology, as a methodological leap forward for mankind's probe for society, will definitely reveal its effectiveness in enterprise operation, government management and scientific mass communication through cloud accounting. This paper firstly elaborates on the influence that cloud accounting and big data have on enterprise's comprehensive budget management. Then, it builds a framework of enterprise's comprehensive budget management system which will optimize the budgeting, budget enforcement, budget adjustment and budget evaluation procedure, and ultimately realize the rational allocation of enterprise resources.
\end{abstract}

\section{Introduction}

With the continuous innovation and development of advanced information technology and application mode in modern society, there is an unprecedentedly rocketing growth in the global data. In the era of big data, the amount, the complexity and the generation speed of data are far beyond the traditional data forms and also beyond the current processing capacity. [1] Cloud computing is a new computing model based on Internet-related services, to efficiently provide users with the resources they need. By setting up a cloud computing platform, enterprises can select and integrate massive data with which to establish various strategic analysis models. In the July of 2016, Ministry of Finance released the "Basic Guidelines for Management Accounting”, which marked a new stage of development for China's management accounting system. [2] The comprehensive budget management is essential to enterprise's operating management and is one of the core contents for their strategic development. [3] In the meantime, cloud computing provides a new opportunity for the establishment of enterprise's comprehensive budget management system in the era of big data.

\section{The connotation of cloud accounting in the view of big data}

Big data not only refers to the huge amount of data, but also the significance of their potential value. In recent years, with the development of information technology, people have created a huge amount of structured, semi-structured and unstructured data that can be presented in HIV, namely Volume, Variety, Velocity and Value. [4] Cloud computing means to provide enterprises with convenient and required web services through the charge to integrate the network, server, data analysis and application software. [5] It is the fruit of distributed computing, parallel computing, network computing, and utility computing. On the other hand, cloud accounting means under big data, the application of cloud computing technology to build a virtual accounting information system (AIS) can provide reliable, timely and relevant information and finally accomplish the financial accounting and accounting management.

The comprehensive budget management is a mode for modern enterprises. [6]Through the process of budget goals, budget forecast, budget enforcement, budget adjustment and budget appraisal to quickly adapt to changes in the market environment, realize efficient allocation of 
resources, strengthen the control and planning, and improve business operation and management.

With the rapid development of information technology, using cloud accounting under big data to effectively dig out the valuable information among massive data and to support budget management have become an important way to improve the level of total budget management.

\section{The influence that cloud accounting has on the comprehensive budget management}

The comprehensive budget of modern enterprises is strategy-oriented. [7] According to the formulated strategic goals, the budget department decomposes the goals into specific budget targets through the budget management committee and allocates all the units, departments and resources. It requires the participation of all people to integrate all the contents of the enterprise in a management system, and additionally, to form a complete service chain.

The core value of cloud is to solve the service issues failed by the current technology and to provide more convenient consumption (such as service issues from multi-tenancy users) and information integration capabilities (such as information integration related to geographic location or to the consumer's personal preference). Therefore, cloud computing can build its own internal clouds or rent the external clouds. This technology can be adopted by both large enterprises and small and medium-sized enterprises.

Cloud computing has given a solution to the problems that arise in the practical application of enterprise's comprehensive budget management. By the use of cloud computing technology, enterprises can simplify and optimize the budgeting, budget adjustment and analysis, establish a comprehensive budget management information system based on cloud platform and an information management platform to make sure that the comprehensive budget management will definitely create value for the enterprises and achieve their strategic goals.

\section{Constructing the cloud computing-based comprehensive budget management system}

Cloud accounting under big data helps obtain relevant structured, semi-structured and unstructured data from multiple dimensions and timely give a feedback to the administrator, thus isolated information island among the company departments is avoided. Through distributed processing of cloud accounting, the singular management model is transformed. To build the system by the use of cloud computing technology is to set up budget management modules in the Internet and establish corresponding regulations to optimize the top-down and bottom-up budgeting and the methods. A cloud computing-based comprehensive budget management system is divided into three layers: Infrastructure as a Service (IaaS), Platform as a Service (PaaS) and Software as a Service (SaaS)

Through the cloud accounting platform, the internal and external data information of the enterprise are selected, built, integrated and analyzed in the data analysis layer; a comprehensive budget management plan which suits the diversified characteristics of departments is made in the cloud accounting application layer. With the platform, the information resources are shared by the users. Thus the transfer of information among various departments and management is more convenient; moreover, the approval process is simplified, which is time-saving and efficient. 


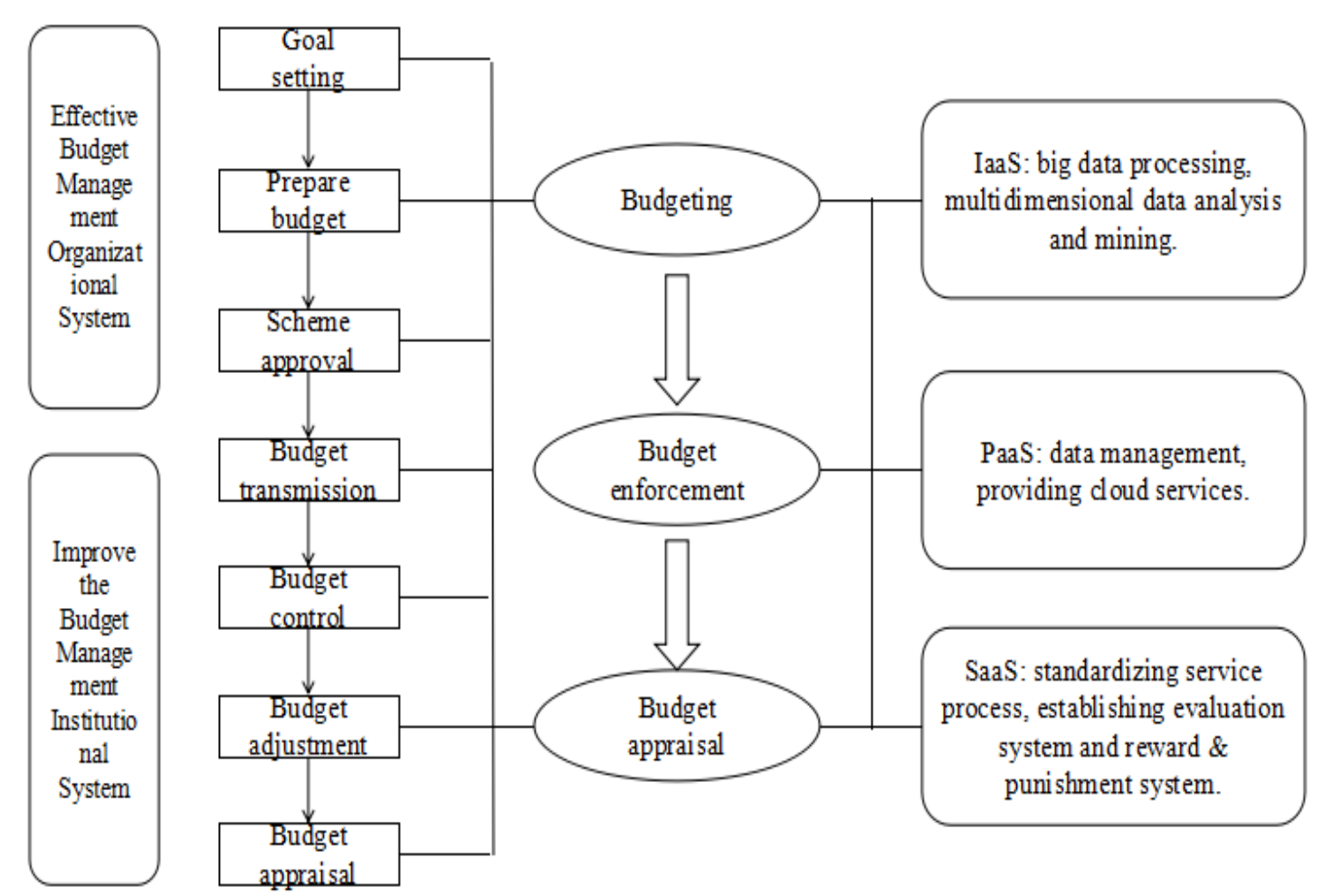

Figure 1. The flow diagram of cloud computing-based comprehensive budget management system

\section{Budgeting}

The budgeting of enterprises conducted with history budget data and relevant industry data offered by cloud accounting can guarantee the facticity and validity of the contents of comprehensive budget management. For example, in the course of purchase budgeting, based on the information obtained from the cloud accounting, the optimal raw material supplier can be determined. Furthermore, the act of purchasing budget from the lower department can be rationally evaluated and the guidelines for comprehensive budgeting can be made. The traditional top-bottom and bottom-top mode of enterprises is changed, which shortens the period of comprehensive budgeting. In addition, corporate managers can use the cloud accounting platform to make accurate judgments on the rationality of budget funds reported by various departments, thus avoiding the acts of concealment and misrepresentation.

\section{Budget enforcement}

a. Budget approval and enforcement control. Budget approval under cloud accounting makes the process standardized and transparent. The inquiry through the cloud platform can put all the duties of budget approval into effect, which avoids both the tardiness of approval process and the arrogation. The risk prediction and analysis of each process can help the monitor management, enhancing the effectiveness of budget control. Business budget data and actual business data are uploaded to the cloud to analyze and compare, thus the business development trend is accurately grasped and the execution effectiveness of budget is guaranteed.

b. Budget adjustment. Enterprises make timely adjustment to the budget through the cloud platform to track the liability, and to solve the problem so that the budget goals can be accomplished.

\section{Budget appraisal}

Based on the cloud accounting under big data, the budget appraisal system can measure the accuracy of budgeting, the reasonability of fund use, the effectiveness of budget enforcement and adjustment. It makes the specific personnel of specific departments has its clearly defined rights and 
responsibilities. In the meanwhile, the cloud accounting has successfully extended the budget appraisal from the responsible departments to the comprehensive budget system, including the budget goals, the budgeting, the budget enforcement and the budget adjustment. Therefore, the enterprise's resources are effectively allocated and the efficiency of comprehensive budget management is improved.

\section{Conclusion}

With the sky rocketing development of economy and the advent of big data era, the traditional budget management is no longer meet the current demands. Therefore, to make full use of the cloud platform, grasp the value of data, and respond to customers' needs have become an inevitable trend. By use of this technology, enterprises can have more effective, accurate and dynamic comprehensive budget management, and finally realize their strategic goals. The application of big data offers a more thorough and reliable data support for comprehensive budget management, which also brings new opportunity and direction for it. This paper demonstrates the influence that big data has on the comprehensive budget management, puts forward the systemic framework for making strategic goals, budgeting, budget enforcement and budget appraisal in order to achieve the reasonable allocation to the enterprise's resources.

\section{References}

[1] Shared interest and honesty in budget reporting[J] . Bryan K. Church,R. Lynn Hannan,Xi (Jason) Kuang. Accounting, Organizations and Society . 2012 (3)

[2]Capital rationing, competition, and misrepresentation in budget forecasts[J] . Alexander Brüggen,Joan Luft. Accounting, Organizations and Society . 2011 (7)

[3]Avoiding Accounting Fixation: Determinants of Cognitive Adaptation to Differences in Accounting Method*[J] . DAVID T.DEARMAN,MICHAEL D.SHIELDS. Contemporary Accounting Research . 2010 (2)

[4]Investigating the effects of computer mediated interruptions: An analysis of task characteristics and interruption frequency on financial performance[J] . K. Asli Basoglu,Mark A. Fuller,John T. Sweeney. International Journal of Accounting Information Systems . 2009 (4)

[5]Beyond budgeting or budgeting reconsidered? A survey of North-American budgeting practice[J] . Theresa Libby,R. Murray Lindsay. Management Accounting Research . 2009 (1)

[6]Features of Activity-Based Budgeting. Bleeker,Ron.Key. Journal of Cost Management . 2001

[7]Profit Planning and Control. Welsh,Budgeting. . 1976 